\title{
ALGUMAS CONTRIBUIÇÕES DAANÁLISE INSTITUCIONAL PARA ESTUDAR AS RELAÇÕES ENTRE OS SERVIÇOS PÚBLICOS DE SAÚDE EA SUA CLIENTELA
}

\author{
CONTRIBUTIONS OF THE INSTITUTIONALANALYSIS TO STUDYTHE \\ RELATIONSHIP BETWEEN STATE HEALTH SERVICES AND ITS \\ CLIENTELE \\ ALGUNAS CONTRIBUCIONES DELANÁLISIS INSTITUCIONAL PARA \\ ESTUDIAR LAS RELACIONES ENTRE LOS SERVICIOS PÚBLICOS DE LA \\ SALUD Y SU CLIENTELA
}

Wilza Rocha Pereira'

\begin{abstract}
RESUMO: Neste artigo expus as contribuições que a linha teórica da análise institucional pode dar para o estudo das inter-relações entre os serviços públicos de saúde, a enfermagem e a sua clientela. Essa linha teórica possui instrumentos que podem não só ampliar a autonomia dos clientes e profissionais como melhorar a qualidade dos serviços prestados. A metodologia adotada foi problematizar primeiramente a questão teórica, através desse ensaio feito a partir dos pressupostos, conceitos e noçőes do Movimento Institucionalista analisados por Gregório Baremblitt.
\end{abstract}

PALAVRAS-CHAVE: serviços de saúde, enfermagem, análise institucional, autonomia, poder

\section{INTRODUÇÃO}

Como trabalhadora em serviços públicos de saúde há mais de quinze anos, percebo e convivo continuamente com uma flagrante assimetria nas inter-relações que neles acontecem. Essa assimetria, traduzida aqui nesse texto como uma quase ausência de democracia, pode ser vista tanto nas relações que ocorrem entre os diferentes grupos profissionais que atuam na saúde, como entre esses últimos e a clientela que acorre aos serviços.

A clientela dos serviços públicos de saúde, mesmo sendo uma maioria quantitativa é, quase sempre vista e entendida como uma minoria qualitativa, pois não dispõe de muitos recursos institucionais ou lingüisticos para questionar a qualidade do atendimento que lhe é oferecido. Por realmente precisar desses serviços prestados pela rede pública de saúde e também por não ter muitos meios para negociar um atendimento mais simétrico ou melhores condições de assistência, a clientela fica a mercê dos modelos autoritários de organização presentes nos SPS e que não a beneficiam, mas não tem onde procurar por outros serviços se aqueles oferecidos não Ihes forem satisfatórios ou não responderem às suas necessidades de saúde.

Devido a essa inquietação permanente e a impressão de que, a cada dia, mais e mais, os profissionais dos serviços públicos de saúde vão aprofundando as assimetrias e a hierarquia hoje vigente, ou seja, impondo a sua lógica sobre as necessidades da clientela, passei a procurar por alternativas teórico-metodológicas que pudessem nos mostrar, como enfermeiras e profissionais de saúde interessadas, que há possibilidades de mudar o equilibrio de forças

Enfermeira-docente e Doutora da Universidade Federal de Mato Grosso - Faculdade de Enfermagem e Nutrição. 
que está posto nestes serviços, no sentido de ampliar a autonomia da clientela nas relações aqui analisadas.

Um dos caminhos que me pareceu promissor para abordar as relações entre clientela, profissionais e serviços de saúde seja pelo seu caráter transformador, seja pelo seu potencial político-pedagógico, é o da análise institucional. Esta corrente de pensamento, pode se dizer, é teórico-prática, pois traz, não só maneiras inovadoras de repensar a realidade social, como também, e, principalmente, vários métodos de intervenção nessa realidade.

A análise institucional tem no seu arcabouço teórico as 'ferramentas' que necessitamos para contrapor as idéias de submissão, de alienação, de 'servidão voluntária', de conformismo consentido, muito trabalhadas por outras correntes teóricas (como a marxista ou a teoria das trocas simbólicas de Pierre Bourdieu, só para citar algumas) quando estas falam da reprodução da lógica de dominação pelos dominados.

Dentre as muitas vertentes teóricas presentes no Movimento Institucionalista, a que me interessa particularmente, é muito bem explicitada por Gregório Baremblitt (1996) em seu livro 'Compêndio de análise institucional e outras correntes - Teoria e prática'. Nesse livro o autor esclarece, de forma extremamente didática, todas as correntes, conceitos, teorias subjacentes ao institucionalismo, bem como aponta suas principais aplicações práticas no cotidiano dos serviços. Esse artigo baseou-se preponderantemente no livro referido.

\section{MOVIMENTO INSTITUCIONALISTA-NOÇÕES E CONCEITOS BÁSICOS}

Os processos de auto-análise ${ }^{2}$ e de autogestão são a "alma" e o "coração" da análise institucional. São processos que visam, em última análise, contribuir para que os indivíduos e as comunidades voltem a ter confiança nos seus próprios julgamentos e recuperem o poder de gerenciar a própria vida nos seus mais variados aspectos, ou seja, espera-se que recuperem a autonomia perdida e possam vir a exercer, de fato, o seu papel de cidadãos.

Diz Baremblitt (1996, p.14), "as diferentes escolas do movimento institucionalista se propõem propiciar, apoiar, deflagrar nas comunidades, nos coletivos, nos conjuntos de pessoas, processos de auto-análise e de autogestão". A auto-análise é um conceito que tem sua origem na psicanálise e consiste, para o autor, em colocar "as comunidades como protagonistas de seus problemas, de suas necessidades, de suas demandas", podendo assim, "enunciar, compreender, adquirir ou readquirir um vocabulário próprio que Ihes permita saber acerca de sua vida" (p.17).

Lembra ainda o mesmo autor que, nas comunidades, os processos de auto-análise ocorrem de forma simultânea com os "processos auto-organização, em que a comunidade se articula, se institucionaliza, se organiza para construir os dispositivos necessários para produzir, ela mesma, ou para conseguir os recursos de que precisa para o melhoramento de sua vida sobre a terra" (p.18).

É importante lembrar que esta organização ocorre num movimento paralelo com a autoanálise e que ela acontece no próprio seio do coletivo interessado, revelando a emergência das suas reais necessidades, não sendo apenas uma manifestação de uma demanda modulada pelos expertos, ou seja, profissionais que dizem às comunidades quais são as "suas necessidades" e que, quase sempre coincidem com os serviços que os profissionais querem ou podem oferecer. As enfermeiras, enquanto profissionais de saúde, também podem ser consideradas como tal se conduzirem as suas relações com a clientela de acordo com seus próprios interesses.

${ }^{2}$ Doravante as palavras específicas da teoria serão colocadas em negrito, quando citadas pela primeira vez. 
Além desses objetivos básicos a análise institucional também trabalha com outros conceitos e noções que relativizam as questões do poder dentro dos coletivos interessados em recuperar sua autonomia, seus saberes e conhecimentos, obtendo assim condições de ter uma melhor qualidade de vida, pois passam de objetos a sujeitos das relaçöes nas quais estão inseridos.

Um dos conceitos básicos da Análise Institucional é o de instituição. Diz Baremblitt (1996, p. 177) que as "instituições são árvores de decisões lógicas que regulam as atividades humanas, indicando o que é proibido, o que é permitido e o que é indiferente. Segundo seu grau de objetivação, podem estar expressas em leis, principios ou fundamentos, em normas ou pautas". É um conceito que, tal como todo o arcabouço da análise institucional, exige um deslocamento teórico aos pesquisadores na área da saúde, pois são exemplos de instituições, no entendimento desse mesmo autor: a linguagem, as relações de parentesco, a religião, o Estado, a educação, a justiça e a saúde, dentre muitas outras.

Lembra o autor que, para uma instituição realizar "concretamente sua função regulamentadora", ela precisa materializar-se em organizações e estabelecimentos. Por exemplo: a instituição educação materializa-se na organização estatal que pode ser o Ministério da Saúde, que define como devem funcionar, não só os estabelecimentos de ensino como também quais são suas obrigações e deveres em uma determinada sociedade.

Para os institucionalistas a sociedade deve ser vista como um "tecido de instituições que se interpenetram e se articulam entre si para regular a produção e a reprodução da vida humana sobre a terra e a relação entre os homens" (Baremblitt,1996, p.29).

É interessante lembrar que as instituições é que informam e formam as organizações, e estas os estabelecimentos. Nestes últimos estão os equipamentos, que são, segundo os institucionalistas, os dispositivos técnicos, tais como as máquinas, as instalações, os arquivos, etc., e é através desses equipamentos que os agentes dão vida às instituições que se materializam, que vão acontecer pela prática de seus agentes.

Os agentes são os protagonistas que dão vida às instituições e eles carregam práticas que podem ser verbais, não verbais, práticas teóricas ou técnicas, podendo ser vistos sempre em vivo dinamismo. São os professores e seus alunos, intermediados pela instituição educação, ou os profissionais de saúde e sua clientela, intermediados pela instituição saúde, agindo nas suas respectivas organizações e estabelecimentos.

Nas instituiçōes -chamando a atenção para não confundir com organização ou estabelecimento-, existem duas vertentes que se contrapõem dialéticamente, a vertente dita instituinte e, por outro lado, sua parte instituida, logo, o instituinte aparece sempre como um processo e o instituído como um resultado. Há uma tensão dialética constante entre esses dois pólos com o instituinte transmitindo uma característica dinâmica, mutável e mutante e o instituído portando uma característica estática, assentada. É o instituído que representa a lei, a ordem e o conhecido, enquanto o instituinte mostra seu lado transformador, criativo, revolucionário, mas sempre informado pelo instituido que o gera e que é regenerado por ele. Quanto mais revolucionária for uma prática, mais elementos instituintes ela agrega e mais contribui para que haja transformações no imaginário social e, por conseguinte, transformações nas instituições e nas relações de poder onde esteja agindo.

Assim temos também o organizado e o organizante, que informam as organizações e que são alimentados pelas instituições que os plasmam e pelos agentes que lhes dão vida. Se o organizante é dinâmico e transformador, o organizado é a burocracia, a permanência, a cristalização. Para ocorrerem transformações em qualquer organização haverá necessidade de uma tensão, e esta pode ser revolucionária ou conservadora, dependendo do nivel de . questionamentos que estão se produzindo dentro da instituição. Se o momento é de muita instabilidade ou anarquia, o desejo será por ordem e vice-versa.

Nós profissionais de saúde somos descritos, com uma certa frequeência, como 
historicamente conservadores, ou seja, contribuimos para a permanência do organizado e freamos a emergência do organizante, uma situação que vem mudando mais significativamente nos locais onde há maior discussão e questionamentos, como nos serviços mais arrojados e que estão visando oferecer maior qualidade assistencial à sua clientela. Há alguns exemplos dessas mudanças relatados nos livros "Inventando a mudança na saúde" de Luiz Carlos de Oliveira Cecílio e "Agir em saúde: um desafio para o público" que tem Merhy e Onocko como organizadores. Ambos os livros relatam trabalhos inspirados na análise institucional.

Há três grandes situações viciosas, no dizer de Baremblitt, que podem por em risco o dinamismo dialético que deveria ser inerente às instituições, são elas: a exploração, a dominação e a mistificação. Estas são maiores deformações que impedem a realização das mais altas aspirações de todas as sociedades, como diferentes formas de liberdade, de igualdade, de verdade e de fraternidade.

Cada sociedade sempre tem uma utopia que é deformada pela exploraçăo de muitos por alguns, sendo que uma das formas mais comuns de exploração é a expropriação da potência, dos saberes, do resultado produtivo de uns pelos ouțros. Um exemplo da expropriação de saberes dá-se no nosso campo de trabalho entre duas práticas de saúde que são hierarquicamente justapostas como é o caso da medicina e da enfermagem. Dentre essas práticas criou-se, socialmente e historicamente, a subalternidade de uma prática em relação a outra, o que ocorreu por várias razőes, tais como problemas relacionados ao gênero feminino e masculino, hierarquia de saberes e de práticas.

Fatos como esses levam o grupo subalterno a construir coletivamente, com o passar do tempo, uma subjetividade sujeitada, na qual não há lugar para o enfrentamento ou para a luta, então há uma remarcação de territórios que sempre beneficia os que já estão na hierarquia superior e o dominado passa a contribuir com o seu dominador, inclusive reforçando a sua própria secundaridade em relação ao outro. Esse processo acontece em todos os campos de produção do grupo sujeitado, seja na produção científica, seja no cotidiano de trabalho, de forma que o grupo sujeitado é completamente envolvido pelo que acredita ser seu destino. A ruptura pode acontecer de duas maneiras: através do desejo intenso por ter uma outra identidade, não sujeitada, fato que passa pelo duplo trabalho de, ao mesmo tempo, desconstruir essa identidade e reconstruí-la sob um outro paradigma, mais conveniente aos novos desejos do grupo.

Outro exemplo comum na área da saúde é a expropriação de potência e dos saberes através da apropriação das práticas nativas de uma comunidade, com sua concomitante negação e a imposição de práticas estrangeiras. Isso é feito de tal forma, que as práticas nativas são perdidas ou esquecidas pela comunidade que as detinha e que, de alguma forma, funcionavam e identificavam o grupo. Podemos ver isso através da destruição da cultura indígena e dos grupos caboclos brasileiros, que estão sendo lentamente destruídos, fazendo parte de um processo onde se tira o que se tinha e se introduz uma prática nova que, aparentemente, pode dar mais respostas aos problemas locais. Um livro clássico da área da saúde que bem descreve esse processo em relação ao processo de medicalização da sociedade é Nêmesis da medicina: a expropriação da saúde de autoria de Ivan Illich (1975).

Outra deformação das instituições que vem associada a expropriação, é a dominação, entendida como a imposição da vontade de uns sobre outros e aliada ao não respeito à vontade coletiva, vindo quase sempre junto à mistificação. Para dominar, é necessário deter algumas formas de conhecimento legitimadas socialmente, ou seja, que tragam consigo o mito de que são a verdade, ao mesmo tempo em que desqualificam os outros saberes ou conhecimentos que estão circulando. É o caso do saber de senso comum e do saber cientifico, este último, mesmo se baseando muito freqüentemente naquele primeiro, sistematicamente o desqualifica como sem fundamentação ou sem valor. Pode-se dominar de muitas formas mas, com certeza, o saber científico é uma das mais poderosas maneiras de se criar mistificações e de explorar 
os demais. Aliar o saber científico ao saber popular na nossa área pode ser uma boa forma de desmistificação da aura que cerca os serviços e os profissionais de saúde.

O grande problema, que nem sempre é muito claro, é que a funçăo das organizações e dos estabelecimentos é de servir o instituido, o organizado e também de que estes estão a serviço da exploração e da dominação. Como exemplo podemos citar a medicina, uma das práticas mais emuladas da área da saúde, na qual pouco se fala nos seus muitos fracassos mas muito se divulgam os seus sucessos e a sua constante superação tecnológica, como se as tecnologias descobertas estivessem facilmente disponiveis a qualquer pessoa. Diz Illich (1975) que se cria assim o mito da vida eterna, da saúde perfeita e, é claro, só com a tecnologia médica se alcançará isso. Nunca se divulga que "é apenas em terceiro lugar que se deve situar o impacto do ato médico sobre a saúde global. Contrariamente ao meio e às técnicas sanitárias não profissionais, os tratamentos médicos consumidos por uma população são uma pequena parte e jamais ligada significativamente à redução do peso da morbidade ou do prolongamento da esperança de vida. Nem a proporção de médicos numa população, nem os meios clínicos de que esta dispõe, nem o número de leitos hospitalares, ocasionam mudança profunda das estruturas globais da morbidade. (Illich. 1975, p 24).

$\mathrm{Na}$ construção de uma vida saudável é de enorme importância, segundo o autor, as condiçöes de vida e de meio ambiente, incluindo ai o modo de vida, as condições de alimentação, de habitação, de trabalho, a coesão do tecido social e os mecanismos culturais que permitem estabilizar a população, esses sendo fatores decisivos na determinação do estado de saúde de uma população, vindo em seguida as condiçōes de saneamento, muito menos importantes e com menor destaque que àquelas primeiras.

Os meios de comunicação contribuem enormemente para essa mistificação de algumas áreas e a emulação de algumas classes profissionais, o que se dá através da divulgação de sua função social, só que esta função declarada raramente se materializa como ela é de fato, justamente por causa da mistificação, sendo comum apresentá-la como um objetivo natural, desejado, e evidentemente lógico da organização. É o caso dos objetivos maiores que sempre se encontram traçados nas principais organizações sociais, mas que, de fato, jamais se pretende que sejam alcançados, a exemplo temos os objetivos do Sistema Único de Saúde, totalmente desfigurados por interesses outros que não os das populações que dele se utilizam.

Em contraposição à função, que está, segundo o institucionalismo, sempre a serviço do instituido, do organizado, do que está posto, cristalizado, temos o funcionamento. Este pode ser definido como forças, processos sempre inspirados na utopia, na perseguição dos objetivos maiores de bem-estar social. Se a função é conservadora, reacionária, o funcionamento tende a ser justiceiro, utópico, revolucionário. Mas, é importante lembrar, que a função é o avesso do funcionamento mas que ambos devem coexistir dialeticamente, pois um inspira e realimenta o outro.

Temos então conformando e informando a instituição de um lado, o instituido, o organizado, a função e, do outro, o instituinte, o organizante e o funcionamento. Se os primeiros estão a serviço da reprodução, da manutenção do status quo, a serviço do conservadorismo, os segundos, servem, sobretudo, as forças produtivas, revolucionárias, propicias a geração do novo, podendo ser vistos também como espaço para a atuação de enfermeiras e de outros profissionais interessados em mudar o instituído. Diz Baremblitt que:"o institucionalismo pensa que as pequenas conexões locais são o lugar do instituinte, e entendê-lo assim está estritamente relacionado com as estratégias de intervenção nos âmbitos, nos espaços de atuação que o institucionalismo vai tentar propiciar. Eles são os pequenos lugares intersticiais da vida naturalsocial-técnica e subjetiva e não os grandes blocos representativos dos territórios constituídos" (1999, p.46).

Os chamados territórios constituídos são o lugar privilegiado do instituído, do organizado, da antiprodução, que vem a ser a captura, o enclausuramento das forças produtivas, instituintes, 
que são enterradas nos grandes organismos como o Estado, o govemo, a igreja. Nesse processo antiprodutivo as forças são:"Voltadas contra si mesmas, de maneira que a produção, as energias não orientadas, as matérias produtivas ainda näo formadas são retidas pelos mecanismos, pelos equipamentos, pelos organismos de toda ordem que propiciam a reprodução do mesmo, o impedimento ou a destruição do novo, elas tornam-se antiprodutivas, elas se destroem a si mesmas" (Baremblitt,1999, p.46)

São exemplos dessas forças antiprodutivas: as guerras, destruição de alimentos porque o preço caiu no mercado. São atitudes ativas de algumas minorias conservadoras que levam multidões em direção à miséria, à marginalidade, que criam os preconceitos, a tóxicodependência, por exemplo. Mas, por outro lado, a maioria explorada cria, constantemente, estratégias das mais diversificadas para fazer frente àquela minoria, que pode ir desde provocar constrangimentos até chegar a enfrentamentos mais explícitos, sendo sempre mais eficientes quanto mais representem os coletivos que a eles subjaz.

Nos espaços dos serviços públicos de saúde impera a antiprodução e nós, enquanto profissionais de saúde, em muito contribuímos para a permanência do instituido, do organizado, da função mistificada desses serviços. Como sair desse torvelinho e partir para a produção de subjetividades instituintes, produtivas, libertárias? Será que nós enfermeiras temos condições de fazer isso?

\section{A ENFERMAGEM, O DESEJO E AS POSSIBILDADES DE MUDANÇAS}

Como trabalhadoras, nós enfermeiras, somos sujeitos coletivos. Mas o fato de sermos sujeitos coletivos não nos coloca automaticamente como sujeitos políticos, pois para que sujeitos políticos se constituam há necessidade de agenciamentos diferentes daqueles que constituem os sujeitos sociais, diferença essa que se inscreve nas formas singulares de se produzir subjetividades. Como nos diz Guatarrie Rolnik:"a subjetividade está em circulação nos conjuntos sociais de diferentes tamanhos: ela é essencialmente social, e assumida e vivida por individuos em suas existências particulares. O modo pelo qual os individuos vivem essa subjetividade oscila entre dois extremos: uma relação de alienação e opressão, na qual o indivíduo se submete à subjetividade tal como a recebe, ou uma relação de expressão e criação, na qual o individuo se reapropria dos componentes da subjetividade produzindo um processo que eu chamaria de singularização"(1993, p. 33).

Ao discorrer sobre como os individuos vivem os processos de subjetivação, acredito que o autor acima citado o faça de forma um tanto radical, pois me parece pouco provável que alguém se submeta totalmente a esses processos de formação da "subjetividade tal como a recebe", por isso a relativização que Campos (1994) faz a esse respeito me parece mais alvissareira. Afirma este autor que podemos ter a constituição de sujeitos sociais singulares e revolucionários, isso por serem dotados de desejo e vontade política para "alterar a correlação de forças" tal como elas se dão nos ambientes de trabalho. Essas alterações podem ocorrer de várias maneiras, mas todas requerem de forma precipua: 'a constituição de atores que neguem a inevitabilidade da permanência do status quo, que entrevejam possibilidades de alterá-lo e que, principalmente, se sintam com direito de desejar esta mudança". (Campos, 1994, p. 67).

A questão do desejo é fundamental para o movimento institucionalista e é essa concepção que faz com que as diferentes escolas desse movimento se proponham propiciar, apoiar ou deflagrar nas comunidades e nos coletivos sociais a emergência de processos de auto-análise e processos de auto-gestão que estimulem a percepção de que $o$ "viver cotidiano não precisa, obrigatoriamente ser aquele da repetição, da renúncia sistemática à autonomia e ao desejo", conforme nos lembra Campos (1994, p. 67).

Penso que podemos nos fazer algumas perguntas, como profissionais da área da saúde: como anda o nosso desejar enquanto enfermeiras? Quais as nossas potencialidades/ 
possibilidades nesse campo? Quais os espaços que nos damos o direito de ocupar? Ou melhor: quais os espaços que queremos, de fato, ocupar? Qual o nosso espaço enquanto enfermeiras?

Um espaço que sempre nos é dado (na verdade um espaço pelo qual lutamos um bom tempo) é o de gerenciamento e o de supervisão de serviços de enfermagem. Percebemos nesse espaço a possibilidade de uma micro-revolução, como diria Guatarri (1993), onde poderiamos criar a pulsão, o desejo de que as enfermeiras ao chegarem a esses postos, não só ocupá-los mas, a partir deles, produzir mudanças. Desejo este calcado menos na ambição pelo poder e mais na vontade de produzir mudanças criativas, que considerem o humano, 0 afetivo, o relacional como elementos fundamentais na gestão de serviços de saúde sem, contudo, cair na esparrela de manter o instituído, o organizado e sim investindo para: "fazer surgir ali, onde não existia antes, algo que brota de dentro de nós, movido a desejo, a pulsão (...) tomemos a pulsão como força motora do psiquismo, que necessita de objetos, sobre os quais incidir, para dar-lhe rumo, adjetivá-la. Quando estes faltam, ou são insuficientes, os sujeitos os cria. Inventa. Arquiteta. Constrói. Faz" (Melo,1996, p. 134).

Nos processos instituintes as comunidades tornam-se, sobretudo, as protagonistas de seus problemas, das suas necessidades, de suas demandas, podendo assim vir adquirir ou readquirir um vocabulário próprio que lhes permita melhor entendimento acerca de sua própria existência e de suas reais necessidades.

Percebo enquanto enfermeira, que a nossa procura por algo que nos dê rumo, que nos adjetive, que nos ajude a construir nossa própria identidade nos muitos trabalhos que vêm sendo feitos a partir dos conceitos que exprimem a gênese do nosso fazer cotidiano: o cuidarcuidado e o cuidar-confortar. Um sem número de trabalhos vêm sendo desenvolvidos nessa direção, linhas de pesquisa já foram criadas, evidenciando a força da ruptura que estamos fazendo em relação ao paradigma bio-médico e mostrando o nosso caminhar em direção ao humano, ao nosso próprio paradigma (TEXTO E CONTEXTO, 1998).

Nós, enfermeiras, podemos não só participar desses processos, mas, sobretudo, criar, inventar, arquitetar, construir, fazer surgir condições para que o instituinte, o organizante, o novo, o singular, o revolucionário irrompam e mudem as (assimétricas) relações que hoje estão postas nos serviços de saúde. Sensibilidade e comprometimento para tal não nos faltam.

ABSTRACT: This article points out the contributions that the theory of institutional analysis can give on the study of the inter-relations between state health services and its clintele. This theoretical model has instruments that can increase the autonomy of clients and professionals, as well as improve the quality of the services provided. The methodology adopted questions the theoretical model through this essay which adopted pressupositions, concepts and ideas from the Institutionalist Movement by Gregório Baremblitt

KEYWORDS: health services, nursing, institutional analysis, autonomy, power

RESUMEN: En el artículo expongo las contribuciones que la linea teórica del análisis institucional puede dar para el estudio de las interrelaciones entre los servicios públicos de salud, la enfermeria y su clientela. Dicha línea teórica posee instrumentos que pueden no sólo ampliar la autonomia de los clientes y profesionales como también mejorar la calidad de los servicios prestados. La metodologia adoptada trata de, primeramente, problematizar la cuestión teórica a través de ese ensayo hecho a partir de los presupuestos, conceptos y nociones del Movimiento Institucionalista que son analizados por Gregório Baremblitt.

PALABRAS CLAVE: servicios de salud, enfermeria, análisis institucional, autonomia, poder 


\section{REFERÊNCIASBIBUOGRÁFICAS}

BAREMBLITT, G. Compêndio de análise institucional e outras correntes. 3. ed. Rio de Janeiro: Rosa dos Tempos, 1996.

CAMPOS, G.W.de S. Consideraçōes sobre a arte e a ciência da mudança: revoluçăo das coisas e reforma das pessoas. O caso da saúde. In: CECILIO, L. C. de O. (Org). Inventando a mudança na saúde. São Paulo: HUCITEC, 1994.

GUATARRI, F: ROLNIK,S. Micropoliticas - cartografias do desejo. Petrópolis: Vozes, 1993.

ILLICH, I. A expropriaçăo da saúde: nêmesis da medicina. 3. ed. Rio de Janeiro: Nova Fronteira. 1975.

MELO, R.C. Hả devir, há de vir - Ou o advir do processo de criação terapêutico. In: BAREMBLITT, G. (Org.) Saúde e Loucura n5: A clinica como ela è. São Paulo: Hucitec, 1996.

REVISTA TEXTO \& CONTEXTO. Florianópolis, UFSC, v. 7, n. 2, 1998. 425p. 